\title{
Fast preparation of a polyclonal antibody against chicken protocadherin 1
}

\author{
Y.H. Li ${ }^{1 *}$, X.H. Zhao ${ }^{1 *}$, M. Li ${ }^{1}$, C.Q. Yang ${ }^{1}$, L. Wang ${ }^{2}$ and J.T. Lin ${ }^{1,3}$ \\ ${ }^{1}$ Henan Cultivating Key Laboratory of Heredity Disease and Targeted \\ Molecular Drugs, School of Life Sciences and Technology, \\ Xinxiang Medical University, Xinxiang, Henan Province, China \\ ${ }^{2}$ School of Basic Medical Sciences, Xinxiang Medical University, \\ Xinxiang, Henan Province, China \\ ${ }^{3}$ Institute of Anatomy I, University of Jena School of Medicine, \\ Jena University Hospital, Jena, Germany \\ *These two authors contributed equally to this study. \\ Corresponding authors: J.T. Lin / Y.H. Li \\ E-mail: linjuntang2002@yahoo.co.uk / yonghaili@126.com
}

Genet. Mol. Res. 12 (2): 2156-2166 (2013)

Received January 14, 2013

Accepted May 12, 2013

Published June 28, 2013

DOI http://dx.doi.org/10.4238/2013.June.28.3

\begin{abstract}
Protocadherins constitute a large family belonging to the cadherin superfamily; they function in various tissues of a wide variety of multicellular organisms. However, their functions and expression modes are still unknown in many of these species and tissues. We developed a fast and low-cost method to produce polyclonal antibody against chicken protocadherin 1 (Pcdh1) that could be used in assays for immunological assessment of protein expression levels of chicken Pcdh1. Primers were designed with DNAStar, using the nuclear sequence of $p c d h 1$ as a template; the $p c d h 101$ fragment was amplified, identified by sequencing and cloned into expression vectors pGEX-2TK and pET-32a, separately, resulting in 2 recombinant plasmids, pGEX-2TK-pcdh101 and pET32a-pcdh101. These were confirmed by double-enzyme digestion and sequencing. The recombinant expression vectors were transformed and expressed in Escherichia coli BL21. The recombinant oligopeptides
\end{abstract}


glutathione-S-transferase (GST)-Pcdh101 and (His) ${ }_{6}$-Pcdh101 fused with the carrier protein GST and (His) ${ }_{6}$ separately, and were purified. Rats were immunized by injecting the emulsified GST-Pcdh101 antigen subcutaneously into their hind footpads, followed by a booster injection after 2 weeks. One week after the booster, the sera were collected and examined for antibody titer by indirect ELISA. The optimal dilution of this antiserum was 1:300. The specificity of the antiserum was confirmed by Western blotting. This antiserum had good specificity and could be used to detect chicken Pcdh1 in Western blot analysis. This method allows production of specific rat polyclonal antisera for Western blots in less than 1 month at a relatively low cost.

Key words: Pcdh1; Rat polyclonal antibody; Western blotting; ELISA

\section{INTRODUCTION}

Protocadherins (Pcdhs) are a group of transmembrane proteins with homophilic binding activity, and they are the largest subgroup within the cadherin superfamily of calcium-dependent cell-cell adhesion molecules (Sano et al., 1993). More than 70 Pcdhs have been found in human and mouse, which are predominantly expressed in the central nervous system (CNS) (Vanhalst et al., 2005).

The Pcdh family can be largely divided into 2 groups based on their genomic structure: clustered Pcdhs, and nonclustered Pcdhs. Clustered Pcdhs consist of alpha-, beta- and gammaPcdh, which are encoded by gene clusters on chromosome 5q31 in the human genome (Hirayama and Yagi, 2006; Yagi, 2008). As with other Pcdhs that do not have a specific clustered genome locus, we shall collectively refer to them here as nonclustered Pcdhs. Nonclustered Pcdhs can be divided into delta-Pcdh and other delta-Pcdh. Redies et al. (2005) confirmed and named the delta-Pcdh subfamily in 2005. Members of the delta-Pcdh subfamily can be further divided into 2 subgroups, delta1-Pcdh and delta2-Pcdh, on the basis of overall homology, number of EC repeats, and conservation of specific amino acid motifs in cytoplasmic domains. Nine Pcdhs have been classified from existing research: Pcdh1, 7, 9, and $11(\mathrm{X} / \mathrm{Y})$ in the delta1 subgroup, and Pcdh8, 10, 17, 18, and 19 in the delta2 subgroup (Vanhalst et al., 2005; Redies et al., 2005). Pcdh1 (previously called protocadherin-42) was one of the first Pcdhs identified by reverse transcription-polymerase chain reaction (RT-PCR) with degenerate cadherin primers by Shintaro Suzuki's group (Sano et al., 1993). In transfected cells, it localizes to cell-cell junctions and mediates weak homophilic cell-cell adhesion (Sano et al., 1993; Yamagata et al., 1999). In the rat, Pcdh1 is strongly expressed in the brain (Sano et al., 1993). Its expression was also found in endothelial cells of adult mouse lung (Hirano et al., 1999).

Delta-Pcdh mainly mediate cell-cell adhesion and participate in transmembrane signal transduction (Redies et al., 2005). Members of the delta1-Pcdh subgroup appear to exercise tightly regulated functions in the development, regionalization, and functional differentiation of the mouse brain (Vanhalst et al., 2005). In particular, in vitro adhesive activity has been demonstrated for Pcdh1 (Sano et al., 1993), 7 (Yoshida, 2003), 8 (Obata et al., 1995), and 10 (Favre et al., 2003). Moreover, by preferring homo- over heterophilic interactions, some delta-Pcdh are able to mediate cell sorting in cell culture [e.g., Pcdh1 (Sano et al., 1993) and 10 (Favre et al., 2003] and can do this in vivo as well. 
Studies on delta-Pcdh have increased in recent years. Some mutations of $p c d h$ genes have been linked to human disease. Abnormalities in delta- $p c d h s$ genes may be responsible for the pathogenesis of several neurological disorders and carcinogenesis. For instance, Koppelman et al. (2009) found that $p c d h 1$ was a susceptibility gene for bronchial hyperresponsiveness, and Koning et al. (2012) found that $p c d h 1$ was a novel susceptibility gene for asthma that is expressed in airway epithelium. Philibert et al. (2012) found that the deficiency of $p c d h 12$ led to modifications in the structure and function of arteries. In particular, several lines of evidence indicate that the dysfunction of delta-Pcdhs is associated with some cognitive dysfunction. The homozygous deletion within a protocadherin cluster proximal to $p c d h 10$, which is between the $p c d h 10$ and $p c d h 18$ loci on $4 \mathrm{q} 28.3$, has been shown to be significantly associated with the pathophysiology of cognitive impairment (Morrow et al., 2008). Pcdh17 has been shown to play a part in the pathogenesis of schizophrenia (Dean et al., 2007).

It would be interesting to study expression of $p c d h 1$ in chicken brain further. The establishment of an appropriate assay for Pcdh1 protein level is an indispensable step. Protein levels are measured indirectly. Indirect methods include immunohistochemistry, semiquantitative PCR (Lin et al., 2010), Western blotting, and ELISA (Zhao et al., 2012). Due to the complexity of protein composition in chicken embryo, it is difficult to isolate Pcdh1, so indirect detection is more applicable. Therefore, it was necessary to produce an antibody.

\section{MATERIAL AND METHODS}

\section{Animals}

Ten-week-old female Wistar rats (provided by the animal center of Xinxiang Medical University) were used for immunization. They were maintained under 12-h light/12-h dark laboratory conditions with free access to standard food and water. Each stage of chicken embryos [E4 (4 days of incubation), E4.5, E5.5, E6.5, E7.5, E8.5, E9, E10, E11.5, E12, E13] were provided by the laboratory of Dr. Juntang Lin. All procedures were performed in accordance with the Guidelines for the Care and Use of Laboratory Animals by the Ethics Committee of Xinxiang Medical University.

\section{Preparation of antigens}

The transmembrane domain of $p c d h 1$ (NCBI Reference Sequence: NM_001045827.1) was analyzed with the Globplot2.3 software. Primers were designed with the DNAStar software. The fragment was selected in the extracellular domains, designated as $p c d h 101$. $p c d h 101$ was derived from nucleotide position $97-612 \mathrm{bp}$ in the ORF. The primers for $p c d h 101$ were: P1 5'-TCCTGCCTGGCCCTGTGGTTCCTCT-3' and P2 5'-CTCGGGGCCAGCCAGCAGTTCATA-3'. Restriction sites for BamHI and EcoRI were separately introduced into 5 terminals of the primers. Total RNA from chicken embryonic brains (E7) was extracted using TRIzol reagent according to manufacturer instructions (Bio Basic Inc., Canada) and cDNA was amplified by RT-PCR following the user manual of the Fermentas RevertAid First Strand Synthesis Kit. Standard PCR for $p c d h 101$ amplification was performed at $95^{\circ} \mathrm{C}$ for $15 \mathrm{~min}$ for pre-denaturation, followed by 30 cycles of amplification (denaturation at $94^{\circ} \mathrm{C}$ for $45 \mathrm{~s}$, annealing at $65^{\circ} \mathrm{C}$ for $45 \mathrm{~s}$, and extension at $72^{\circ} \mathrm{C}$ for $45 \mathrm{~s}$ ) and a final extension at $72^{\circ} \mathrm{C}$ for $5 \mathrm{~min}$. The PCR product was analyzed on $0.8 \%$ agarose gels. 
The amplified target sequence was purified and cloned into pGEM-T Easy vector. The recombinant vector was introduced into Escherichia coli JM109 and identified by sequencing. The fragment was obtained by digesting the recombinant vector with Bam HI and EcoRI and cloned into pGEX-2TK at the BamHI and EcoRI restriction enzyme sites. Recombinant colonies were analyzed by PCR and identified by double-enzyme digestion and sequencing.

The constructed vector was then introduced into the E. coli BL21 and a transformed colony was picked up and grown in LB containing ampicillin medium up to an optical density of $0.5\left(\mathrm{OD}_{600 \mathrm{~nm}}\right)$ at $37^{\circ} \mathrm{C}$. Expression of the recombinant oligopeptide fused with the carrier protein GST (glutathione S-transferase) was induced by adding $0.1 \mathrm{mM}$ isopropyl-1-thio-Dgalactopyranoside to the medium, and the bacteria were further incubated for $6 \mathrm{~h}$ at $21^{\circ} \mathrm{C}$. The bacteria were collected and disrupted with ultrasound in PBS (phosphate-buffered saline, $\mathrm{pH}$ 7.5) under low-temperature conditions, and the supernatant was collected from the lysate at $12,000 \mathrm{rpm}$ for $10 \mathrm{~min}$. The supernatant containing the soluble recombinant GST-fused oligopeptide (subsequently called the recombinant protein) for Pcdh101 was incubated with Glutathione Sepharose 4B (GE Healthcare) at $4^{\circ} \mathrm{C}$ for about $2 \mathrm{~h}$. The complex of the recombinant protein and Glutathione Sepharose 4B was washed with PBS for $1 \mathrm{~h}$. Afterwards, the recombinant protein was eluted with $10 \mathrm{mM}$ reduced glutathione in $50 \mathrm{mM}$ Tris- $\mathrm{HCl}, \mathrm{pH} 8.0$, for 2 $\mathrm{h}$. The purity and molecular weight of the recombinant protein was estimated by $12 \%$ sodium dodecyl sulfate-polyacrylamide gel electrophoresis (SDS-PAGE), but the concentration was detected by the Bradford method with a micro-spectrophotometer (Thermo) at $\mathrm{A}_{595 \mathrm{~nm}}$. The purified protein was dried in a freeze-dryer (Christ Corp.).

\section{Immunization of rats and production of polyclonal antibodies}

The immunization of the rats was performed as described elsewhere (Wakayama et al., 2006). Female Wistar rats were anesthetized with sodium pentobarbital (75 mg/kg body weight) by intraperitoneal injection, and $100 \mu \mathrm{L}$ peripheral blood was drawn from the tail vein for preparation of preimmune serum. Three rats were immunized with the same antigen. Each rat was injected subcutaneously in the hind footpads with $200 \mu \mathrm{L}$ emulsion containing $200 \mu \mathrm{g}$ recombinant protein as antigen in physiological saline mixed with Freund's complete adjuvant (Sigma) at 1:1 (v/v). After 2 weeks, the animals were boosted with the same amount of antigen emulsified with Freund's complete adjuvant. Another week after the booster, the animals were sacrificed by deep anesthesia with anhydrous ether, and whole blood was collected through the femoral vein. The antiserum was separated by letting the blood stand for $30 \mathrm{~min}$ at $37^{\circ} \mathrm{C}$ (with absolutely no shaking), followed by centrifugation at $2000 \mathrm{rpm}$ for $20 \mathrm{~min}$. The antiserum was supplemented with $0.05 \%$ sodium azide, equally aliquoted into tubes, and stored at $-80^{\circ} \mathrm{C}$.

\section{Indirect ELISA analysis}

Negative control, positive control, and experimental groups were established in ELISA analysis. (His) ${ }_{6}-101$-purified protein was used as antigen in the negative control group, and in which preimmune serum was used as primary antibody. GST and (His) ${ }_{6}-101$ proteins were used as antigens in positive control and experimental groups, respectively, and in which rat-anti GST-Pcdh101 was used as primary antibody. Each group had a blank 
control without primary antibody. The (His) ${ }_{6}-\mathrm{Pcdh} 101$ and GST proteins were diluted with coating buffer to final concentrations of 5,10 , and $15 \mu \mathrm{g} / \mathrm{mL}$, which were used to coat ELISA plate at $4^{\circ} \mathrm{C}$ overnight. Preimmune serum and antiserum were diluted 1:300, 1:500, $1: 1000,1: 3000$, and $1: 5000$. The antigens were incubated with primary antibody at $37^{\circ} \mathrm{C}$ for 2-3 h. After washing, they were further incubated with horseradish peroxidase-labeled goat anti-rat IgG antibody (ZSGB-BIO) at a 1:5000 dilution, at $37^{\circ} \mathrm{C}$, for $1 \mathrm{~h}$. Color was developed with TMB, and the reaction was stopped by the addition of $2 \mathrm{M} \mathrm{H}_{2} \mathrm{SO}_{4}$. Absorbance was measured at $450 \mathrm{~nm}$ with an ELISA reader (Thermo, Germany) for experimental group (E), negative control (N), blank control (B), and positive control (P). The antiserum titer was defined as $(\mathrm{E}-\mathrm{B}) /(\mathrm{N}-\mathrm{B})$ greater than 2.1 .

\section{Western blot analysis}

The homogenate sample of brain (E6.5, E7.5, E8.5) and spinal cord (E6.5) tissues from chicken embryo and purified GST-101 and (His) ${ }_{6}-101$ (purified with Ni-NTA Sefinose resin at $37^{\circ} \mathrm{C}$ by adding $1 \mathrm{mM}$ isopropyl-1-thio-D-galactopyranoside) and the total protein of (His) ${ }_{6}-1701$ containing $30 \mu \mathrm{g}$ protein were subjected to SDS-PAGE followed by transfer to polyvinylidene fluoride membrane (Millipore Corp., USA). The blots were incubated with rat anti-chicken GST-101 antiserum at 1:500 dilution at $4{ }^{\circ} \mathrm{C}$ overnight. After washing, the blots were further incubated with horseradish peroxidase-labeled goat anti-rat IgG antibody (ZSGB-BIO) at a 1:5000 dilution, at room temperature, for $1 \mathrm{~h}$. The immunoreaction was detected with X-ray film (Kodak) after treatment of the blots with the chemiluminescent reagent ECL-plus (Thermo, Germany).

\section{Semi-quantitative PCR}

Total RNA of different stages (E4, E4.5, E5.5, E6.5, E7.5, E9, E10, E11.5, E12, E13) from chicken embryonic brains was isolated using TRIzol reagent. RT-PCR was carried out to amplify the cDNA of each stage following the user manual of the Fermentas RevertAid First Strand Synthesis Kit. To investigate mRNA expression of the $p c d h 1$, glyceraldehyde3-phosphate dehydrogenase (GAPDH) was used as an internal control to monitor the amount of RNA. The forward primer for GAPDH was 5'-GGGCTCATCTGAAGGGTGGTGCTA-3' and the reverse primer was 5'-GTGGGGGAGACAGAAGGGAACAGA-3'. The amplification of GAPDH was performed at $95^{\circ} \mathrm{C}$ for 5 min for denaturation, followed by 30 cycles of amplification (denaturation for $45 \mathrm{~s}$ at $94^{\circ} \mathrm{C}$, annealing for $45 \mathrm{~s}$ at $62^{\circ} \mathrm{C}$, and extension for 1 min at $72^{\circ} \mathrm{C}$ ) and a final extension for $5 \mathrm{~min}$ at $72^{\circ} \mathrm{C}$. The fragments of GAPDH and $p c d h 101$ were analyzed on $0.8 \%$ agarose gels.

\section{RESULTS}

\section{Analysis of PCR product}

The PCR product amplified for the construction of expression vectors was analyzed by $0.8 \%$ agarose gel electrophoresis. A 516-bp specific fragment was amplified as shown in Figure 1A. 
A

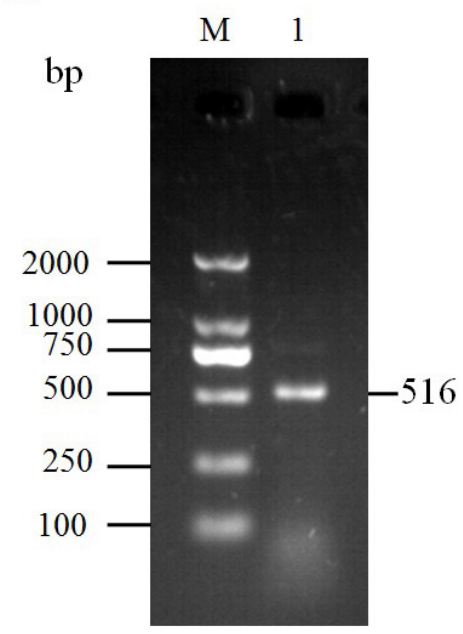

B

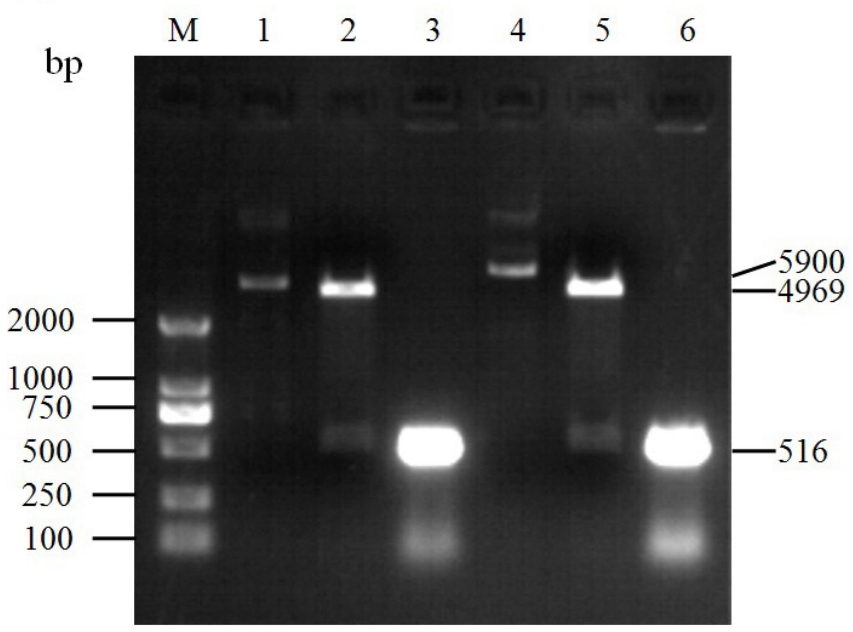

Figure 1. Analysis of PCR amplification product of the 101 fragment and double-digestion pGEX-2TK-pcdh101 and pET-32a-pcdh101 plasmids. A. Lane $1=101$ fragment of Pcdh1; lane $M=$ marker for DNA length. B. Lane $1=$ pGEX-2TK-pcdh101 recombinant plasmid; lane $2=$ pGEX-2TK-pcdh101 digested with BamHI and EcoRI; lane 3 = target fragment of PCR amplification from pGEX-2TK-pcdh101 recombinant plasmid; lane $4=$ pET32a-pcdh101 recombinant plasmid; lane $5=$ pET32a-pcdh101 digested with BamHI and EcoRI; lane $6=$ target fragment of PCR amplification from pET-32a-pcdh101 recombinant plasmid. Lane $M=$ marker for DNA length.

\section{Identification of the expression vectors constructed}

The expression vectors pGEX-2TK-pcdh101 and pET-32a-pcdh101 were doubledigested with BamHI and EcoRI and analyzed by $0.8 \%$ agarose gel electrophoresis. The expected fragment, $516 \mathrm{bp}$, was digested from the expression vectors constructed separately as shown in Figure 1B. They were confirmed by subsequent sequencing.

\section{SDS-PAGE analysis of recombinant protein}

The expressed recombinant protein was analyzed by SDS-PAGE. Bacterial cultures with the null vector pGEX-2TK had a 26-kDa protein band, whereas the culture with the recombinant GST-Pcdh101 expressed a 44.9-kDa band (Figure 2). These bands were consistent with expected sizes, indicating that the fusion proteins were successfully produced. These results also indicated that there was soluble protein in supernatant of the culture. The (His) $)_{6}$ Pcdh101-fused protein $(37.9 \mathrm{kDa})$ was expressed and purified using the same methods (Zhao $\mathrm{XH}$ and $\mathrm{Li} \mathrm{YH}$, unpublished results of our laboratory).

\section{SDS-PAGE analysis of purified protein as antigens}

The purified proteins were obtained after soluble proteins were absorbed with Glutathione Sepharose 4B and Ni-NTA Sefinose resin. The result shown on the SDS-PAGE 
indicated that target protein GST-101 had a higher purity (Figure 3); the result of (His) - $^{-}$ Pcdh101 was not given, but the purity was also high. The Mr 70,000 protein is probably a protein product of the E. coli gene dnak. This protein is involved in protein folding in E. coli. The other proteins were degradation products of GST-Pcdh101.

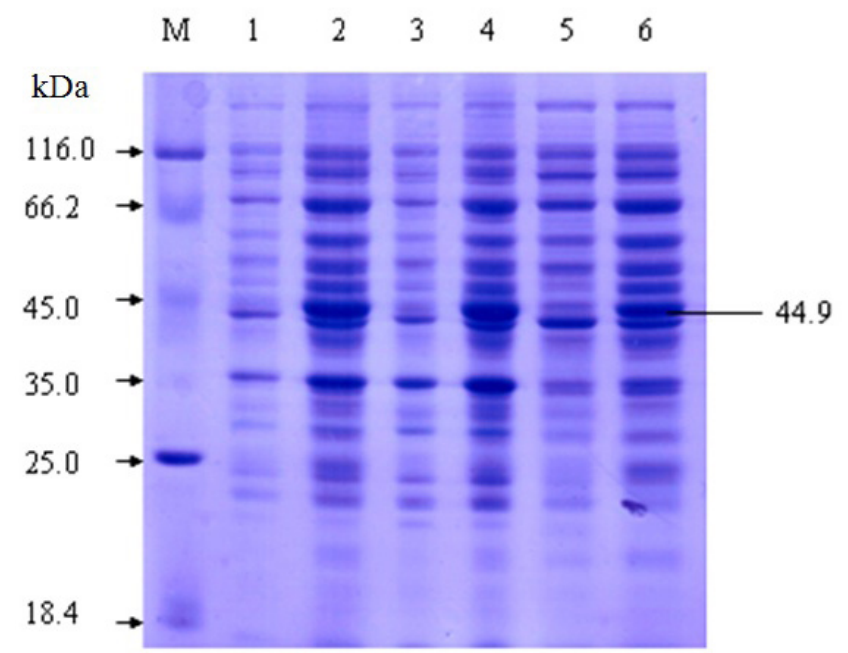

Figure 2. SDS-PAGE analysis of the recombinant GST-101-fused protein. Lane 1 = total protein of GST-Pcdh101 without induction; lane 2 = total protein of GST-Pcdh101 induced by isopropyl-1-D-galactopyranoside (IPTG); lane 3 = deposit of GST-Pcdh101 without induction; lane $4=$ deposit of GST-Pcdh101 induced by IPTG; lane $5=$ supernatant of GST-Pcdh101 without induction; lane 6 = supernatant of GST-Pcdh101 induced by IPTG; lane M $=$ for DNA length.

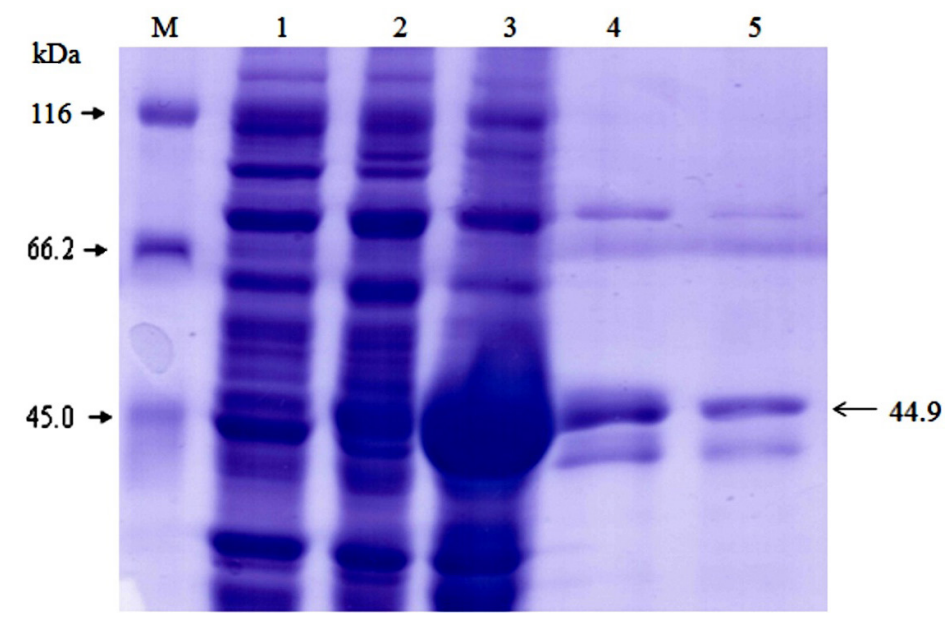

Figure 3. SDS-PAGE analysis of the purified GST-101-fused protein. Lane $1=$ total protein of GST-Pcdh101 without induction; lane 2 = total protein of GST-Pcdh101 induced by isopropyl-1-D-galactopyranoside (IPTG); lane 3 = deposit of GST-Pcdh101 induced by IPTG; lanes 4 and $5=$ GST-Pcdh101 purified protein. Lane $M=$ marker for protein molecular weight. 


\section{Antibody titer analysis}

According to the ELISA results, it was evident that the optimal antigen coating concentration was $5 \mu \mathrm{g} / \mathrm{mL}$, and the optimal dilution of the antiserum was 1:300. Under conditions of optimal antigen coating concentration and optimal dilution of antiserum, the maximal (E - B) / (N - B) criterion of (His) ${ }_{6}$-Pcdh101 was greater than for GST, the same with the other 2 antigen coating concentrations and antiserum dilutions. Thus, it was thought that the polyclonal antibody mainly aimed at the target fragment Pcdh101. Also, indirect ELISA test results indicated that the antibody was effective at more than 1:5000.

\section{Antibody specificity analysis}

On Western blot analysis, GST-Pcdh101 showed a single immunopositive band of about $45 \mathrm{kDa}$ in size and (His) ${ }_{6}$-Pcdh101 about $38 \mathrm{kDa}$ in size (Figure 4A). The Pcdh1 protein expressed in brain and spinal cord of chicken embryo is about $115 \mathrm{kDa}$, which was between 95 and $130 \mathrm{kDa}$ according to the results (Figure 4B).

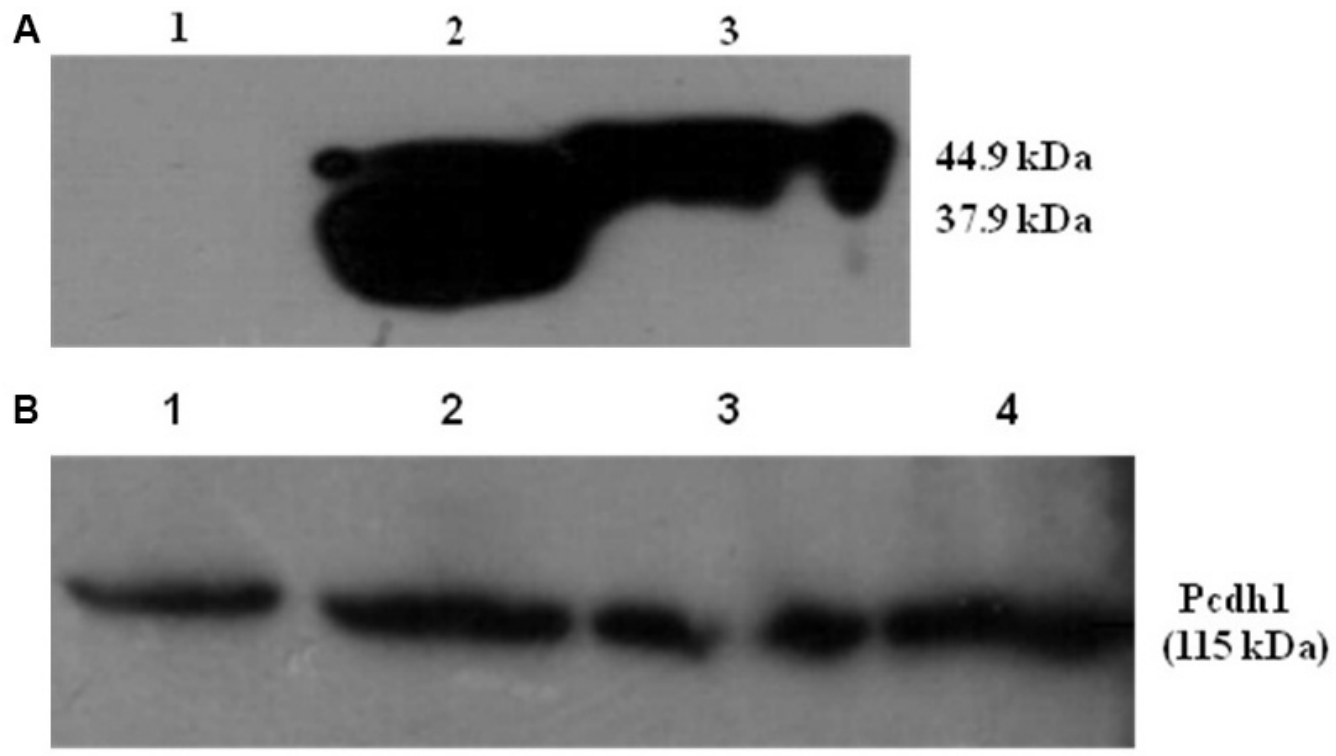

Figure 4. Western blot analysis of antibody specificity. A. Lane 1 = purified His-1701-fused protein; lane $2=$ purified His-101-fused protein; lane 3 = purified GST-101-fused protein. The positions of the molecular weight are indicated. B. Lane 1 = Pcdh1 expressed in spinal cord from chicken embryo (E6.5); lanes 2, 3, 4 = Pcdh1 expressed in brain from chicken embryos at E6.5, E7.5, E8.5, respectively.

\section{Semi-quantitative PCR}

GAPDH are used as an internal control; the same amount of cDNA amplifying GAPDH was used to amplify the $p c d h 101$ in each stage. The result showed that the amount of $p c d h 101$ expressed in the brain of chicken embryo was the most in E9 (Figure 5), and it 
also explained that the amount of the full-length $p c d h 1$ expressed in this stage was the most. From this result, we see that $p c d h 1$ may be expressed from the beginning of development of the chicken embryo.

\section{E4 E4.5 E5.5 E6.5 E7.5 E9 E10 E11.5 E12 E13}

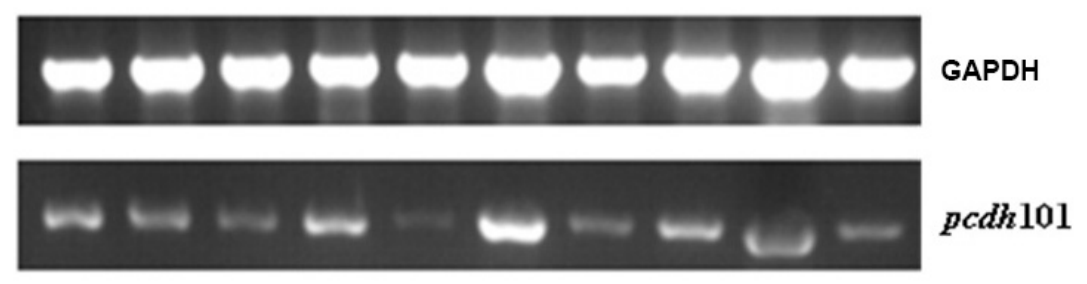

Figure 5. Semi-quantitative polymerase chain reaction analysis showing the amount of $p c d h 101$ expressed at different stages of chicken embryonic development. $\mathrm{E}=$ days of incubation; $\mathrm{GAPDH}=$ glyceraldehyde-3-phosphate dehydrogenase.

\section{DISCUSSION}

Pcdhs are mainly expressed in the CNS, and since the role of Pcdh in neural synapses was discovered, studies on Pcdhs have increased, especially with regard to function. However, there are still many unknown mechanisms.

Now, studies on delta-Pcdh are focused on the expression analysis of a single or several genes and their relationship with some diseases, but recent studies have not been concerned with the following questions: 1) In the process of embryonic development, there is no systematic research on the expression patterns of the delta-Pcdh family in the CNS; 2) The similarities and differences in expression location and evolutionary relationship between species; 3) The regulation mechanism of expression on delta-Pcdh; 4) Abnormal expression of delta-Pcdh can influence the formation and development of the CNS. If the above problems can be answered through basic research, the important basic material will be provided for further study of delta-Pcdh, and the foundation for experiment and theory can be established for the analysis of the relationship between delta-Pcdh and disease, and the guidance can be used for clinical diagnosis and treatment of the diseases associated with these genes. Thus, the preparation of a Pcdh polyclonal antibody is necessary for subsequent research.

This topic mainly uses chicken embryos and rats as experimental animals. Chicken embryo is one of the important experimental animal models in the research field of embryonic development and molecular biology. Compared with the other experimental animals, chicken embryo has many advantages, such as short development cycle, explicit genetic physiological background, simplicity, easily to obtain and handle, and so on (Bellairs and Osmond, 2005). Rats were used for producing the antibody in the laboratory in this case. It is generally thought that the greater the difference between the antigen and species used for immunizing animals, the better the immunogenicity. In addition, the age, weight and cost should also be considered. Also, the polyclonal antibody could not be prepared on a large scale in the laboratory, so we chose the rat as the immune animal. 
In the process of GST-fused protein purification, some other protein could combine with resin (Glutathione Sepharose 4B) or target protein in disulfide bond forms. Protein bound to the target protein is also absorbed by the resin. Thus, non-target protein will be washed off when target protein is eluted. Therefore, to reduce the non-target protein, $5 \mathrm{mM}$ DL-dithiothreitol was added to the binding buffer and elution buffer. DL-dithiothreitol is a reducing agent that can prevent the formation of disulfide bonds between proteins. Consequently, the content of non-target protein can be reduced. In E. coli, there is another protein $(70 \mathrm{kDa})$ expressed by itself. This protein could not be removed totally from the purified protein, but this problem could be alleviated using a certain method. It has been reported that this association can be disrupted by incubating the tagged protein with $50 \mathrm{mM}$ Tris-HCl, $2 \mathrm{mM}$ ATP, $10 \mathrm{mM} \mathrm{MgSO}_{4}$, $\mathrm{pH} 7.4$, for $10 \mathrm{~min}$ at $37^{\circ} \mathrm{C}$ prior to loading on Glutathione Sepharose 4B.

Because the GST tag could not be removed from the purified protein, the antibody could also have specificity for GST. In Western blot analysis, we considered that aliquots of the antisera for practical use were absorbed with GST-purified protein, but it was found that the specificity for GST could not be completely eliminated. As a result, to avoid interference of GST and to determine whether the antiserum showed specificity for the target protein, we used (His) ${ }_{6}-101$ in addition. In the antibody titer analysis, (His) ${ }_{6}$-tag fusion protein [(His) ${ }_{6}-$ 101-purified protein] and GST-purified protein were used to coat ELISA plate. Thus, the interference of the GST-tag could be avoided, and the specificity of antibody for the target protein and the GST protein could also be achieved.

In antibody specificity analysis, we found that antiserum could react with Pcdh1 expressed in brain tissues of chicken embryos. To a certain extent, it was illustrated that the preparation of a polyclonal antibody was successful. Because there is higher homology between Pcdh, we also did the analysis of homology with (His) ${ }_{6}-\mathrm{Pcdh} 17$ fusion protein [(His) ${ }_{6}$-Pcdh17 is used to avoid the interference of GST-tag]. It was found that the antibody could not react with (His) ${ }_{6}$-Pcdh17, which indicated that the antibody was not cross-reactive with Pcdh17. Because we could not do the analysis of homology with the other Pcdh, this result was not universal.

\section{ACKNOWLEDGMENTS}

Research supported by the Nature Science Foundation of China (\#31000475).

\section{REFERENCES}

Bellairs R and Osmond M (2005). The Atlas of Chick Development. 2nd edn. Elsevier Academic Press, San Diego, USA.

Dean B, Keriakous D, Scarr E and Thomas EA (2007). Gene expression profiling in Brodmann's area 46 from subjects with schizophrenia. Aust. N. Z. J. Psychiatry 41: 308-320.

Favre CJ, Mancuso M, Maas K, McLean JW, et al. (2003). Expression of genes involved in vascular development and angiogenesis in endothelial cells of adult lung. Am. J. Physiol. Heart Circ. Physiol. 285: H1917-H1938.

Hirano S, Yan Q and Suzuki ST (1999). Expression of a novel protocadherin, OL-protocadherin, in a subset of functional systems of the developing mouse brain. J. Neurosci. 19: 995-1005.

Hirayama T and Yagi T (2006). The role and expression of the protocadherin-alpha clusters in the CNS. Curr. Opin. Neurobiol. 16: 336-342.

Koning H, Sayers I, Stewart CE, de Jong D, et al. (2012). Characterization of protocadherin-1 expression in primary bronchial epithelial cells: association with epithelial cell differentiation. FASEB J. 26: 439-448.

Koppelman GH, Meyers DA, Howard TD, Zheng SL, et al. (2009). Identification of PCDH1 as a novel susceptibility gene for bronchial hyperresponsiveness. Am. J. Respir. Crit. Care Med. 180: 929-935.

Lin J, Luo J and Redies C (2010). Molecular characterization and expression analysis of ADAM12 during chicken 
embryonic development. Dev. Growth Differ. 52: 757-769.

Morrow EM, Yoo SY, Flavell SW, Kim TK, et al. (2008). Identifying autism loci and genes by tracing recent shared ancestry. Science 321: 218-223.

Obata S, Sago H, Mori N, Rochelle JM, et al. (1995). Protocadherin Pcdh2 shows properties similar to, but distinct from, those of classical cadherins. J. Cell Sci. 108 (Pt 12): 3765-3773.

Philibert C, Bouillot S, Huber P and Faury G (2012). Protocadherin-12 deficiency leads to modifications in the structure and function of arteries in mice. Pathol. Biol. 60: 34-40.

Redies C, Vanhalst K and Roy F (2005). delta-Protocadherins: unique structures and functions. Cell Mol. Life Sci. 62: 2840-2852.

Sano K, Tanihara H, Heimark RL, Obata S, et al. (1993). Protocadherins: a large family of cadherin-related molecules in central nervous system. EMBO J. 12: 2249-2256.

Vanhalst K, Kools P, Staes K, van Roy F, et al. (2005). delta-Protocadherins: a gene family expressed differentially in the mouse brain. Cell Mol. Life Sci. 62: 1247-1259.

Wakayama T, Kato Y, Utsumi R, Tsuji A, et al. (2006). A time- and cost-saving method of producing rat polyclonal antibodies. Acta Histochem. Cytochem. 39: 79-87.

Yagi T (2008). Clustered protocadherin family. Dev. Growth Differ. 50 (Suppl 1): S131-S140.

Yamagata K, Andreasson KI, Sugiura H, Maru E, et al. (1999). Arcadlin is a neural activity-regulated cadherin involved in long term potentiation. J. Biol. Chem. 274: 19473-1979.

Yoshida K (2003). Fibroblast cell shape and adhesion in vitro is altered by overexpression of the 7a and $7 \mathrm{~b}$ isoforms of protocadherin 7, but not the 7c isoform. Cell Mol. Biol. Lett. 8: 735-741.

Zhao K, Sun LX, Sun YS and Zhou DP (2012). Preparation of monoclonal antibody against taxol and establishment of ELISA detection method. Chinese J. New Drugs 4: 436-442. 